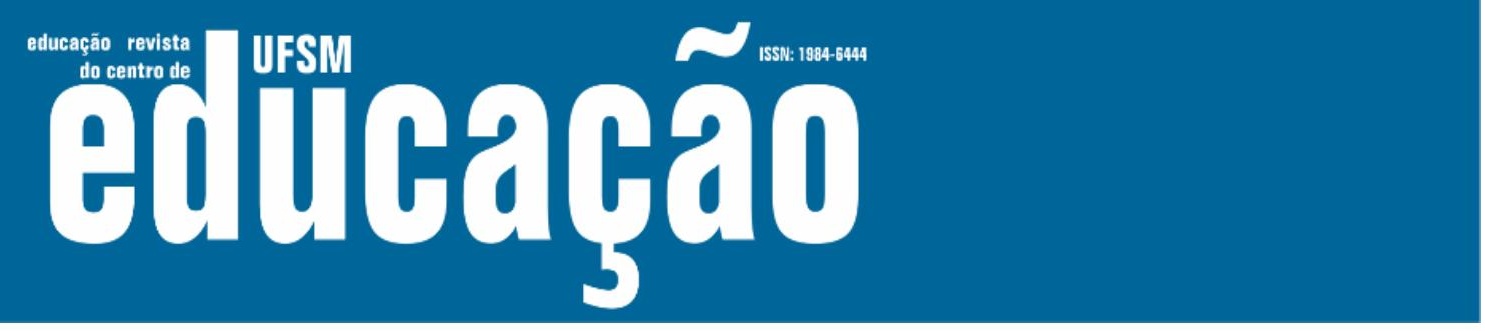

ISSN: 1984-6444 | http://dx.doi.org/10.5902/1984644446906

\title{
Feminismos contemporâneos: mediações e potências do ciberativismo feminista e transfeminista
}

\author{
Contemporary feminisms: mediations and powers of feminist and \\ transfeminist cyberactivism
}

\author{
Maria Helena Santana Cruz \\ Professora Emérita da Universidade Federal de Sergipe, São Cristóvão, Sergipe, Brasil. \\ helenacruz@uol.com.br - orcid.org/0000-0002-7794-278X \\ Ana Paula Leite Nascimento \\ Assistente social do Instituto Federal de Educação, Ciência e Tecnologia de Sergipe, Lagarto, Sergipe, \\ Brasil. \\ paulajcbrasil@yahoo.com.br - orcid.org/0000-0002-2050-1596
}

Recebido em 03 de junho de 2020

Aprovado em 05 de julho de 2021

Publicado em 30 de dezembro de 2021

\section{RESUMO}

O estudo objetivou refletir acerca das expressões contemporâneas dos feminismos, demarcando mediações e potências do ciberativismo feminista e transfeminista. O artigo abordou o pensamento feminista como movimento histórico, político e filosóficoepistemológico e as "ondas" do feminismo; discutiu a respeito das redes de ciberativismo feminista e transfeminista; expôs o retrato da pesquisa sobre feminismo e transfeminismo no Brasil entre 2015 e 2019; e apresentou as expressões dos ciberativismos feministas e transfeministas. Configurou-se uma pesquisa feminista no caráter teórico-metodológico e da práxis, na perspectiva de fortalecer a relação teoria/prática e Universidade/sociedade; qualitativa do tipo bibliográfica e documental; referenciou-se em teorias críticas do feminismo, transfeminismo e marxismo. Recorreu-se à busca on-line: no Portal da Capes pelos descritores feminismo, transfeminismo, ciberativismo feminista, filtrada por Área Avaliação Comunicação e Informação; Educação; e Serviço Social, constatando 324 pesquisas; nas redes sociais do Facebook, Instagram e Twitter com os termos Marcha, Coletivo Feminista e Transfeminista, Frente Feminista e Transfeminista, localizando 438 páginas. A nova "onda" dos feminismos contemporâneos impulsiona novos redesenhos de premissas teóricas e movimentos feministas e transfeministas, estruturados em fronteiras interseccionais, transversais e transdisciplinares de gênero, raça, sexualidade, classe, geração, territorialidade, entre outros marcadores. As produções acadêmicas apontam a apropriação das teorias como subsídio para as práticas sociais, políticas e educativas; e fortalecimento das epistemologias feministas e transfeministas, das agendas reivindicatórias dos feminismos e transfeminismos e das transformações 


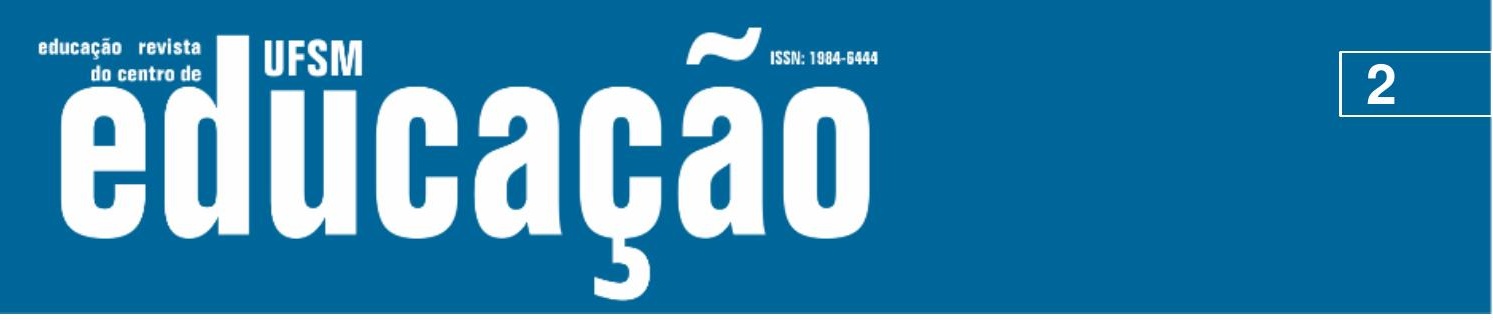

ISSN: 1984-6444 | http://dx.doi.org/10.5902/1984644446906

provocadas. Os ciberativismos feministas e transfeministas intensificam a organização, a mobilização e as resistências das mulheres, culminando em maior diversidade e potência dos levantes nas redes e nas ruas.

Palavras-chave: Feminismos; Transfeminismos; Ciberativismos.

\section{ABSTRACT}

The study aimed to reflect on the contemporary expressions of feminisms, demarcating mediations and potencies of feminist and transfeminist cyberactivism. It approached feminist thought as a historical, political and philosophical-epistemological movement and the "waves" of feminism; discussed the networks of feminist and transfeminist cyberactivism; exposed the portrait of research on feminism and transfeminism in Brazil between 2015 and 2019; and presented the expressions of feminist and transfeminist cyberactivisms. Feminist research was configured in the theoreticalmethodological and praxis character, with the perspective of strengthening the theory/practice and University/society relationship; qualitative bibliographic and documentary type; referenced in critical theories of feminism, transfeminism and marxism. An online search was used: on the Capes Portal by the descriptors feminism, transfeminism, feminist cyberactivism, filtered by the Communication and Information Assessment Area; Education; and Social Service, with 324 surveys; on Facebook, Instagram and Twitter social networks with the terms March, Feminist and Transfeminist Collective, Feminist and Transfeminist Front, locating 438 pages. The new "wave" of contemporary feminisms drives new redesigns of theoretical premises and feminist and transfeminist movements, structured in intersectional, transversal and transdisciplinary boundaries of gender, race, sexuality, class, generation, territoriality, among other markers. Academic productions point to the appropriation of theories as a subsidy for social, political and educational practices; and strengthening of feminist and transfeminist epistemologies, the claiming agendas of feminisms and transfeminisms, and the resulting transformations. Feminist and transfeminist cyberactivism intensifies the organization, mobilization and resistance of women, culminating in greater diversity and power of the uprisings on the networks and in the streets.

Keywords: Feminisms; Transfeminisms; Cyberactivisms.

\section{Introdução}

O movimento feminista contemporâneo, reflexo das transformações do feminismo original - predominantemente intelectual, branco e de classe média configura-se como discurso múltiplo e de variadas tendências, embora com bases 


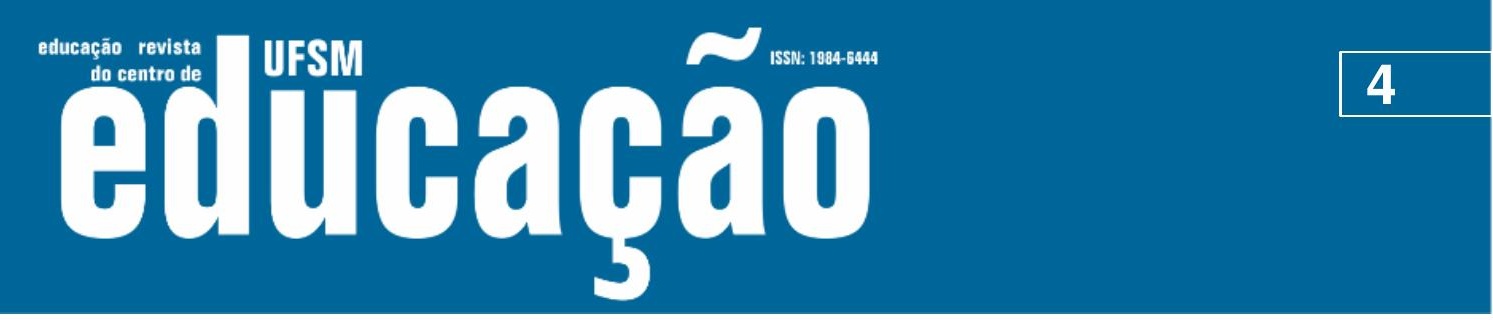

ISSN: 1984-6444 | http://dx.doi.org/10.5902/1984644446906

vidas das mulheres". (CRUZ, 2014, p. 24). Reconhecemos a marcante relevância e o significativo legado dos estudos críticos feministas por terem revelado e exposto as

[...] conexões ocultas entre o privado e o público, permitindo que se observassem vínculos de poder antes desprezados nas tramas macro e micro das relações sociais. O reconhecimento dessa dimensão da desigualdade social, que pode atravessar diversas assimetrias de poder, acarretou vários modos de resistências epistemológicas, práticas e subjetivas, no sentido de tornar visível e inaceitável o que era considerado natural. (CRUZ, 2014, p. 21-22).

O estudo se referenciou também no materialismo histórico dialético, apropriando-se de premissas metodológicas da teoria social marxiana, na qual:

[...] A investigação tem de apoderar-se da matéria, em seus pormenores, de analisar suas diferentes formas de desenvolvimento, e de perquirir a conexão íntima que há entre elas. Só depois de concluído esse trabalho, é que se pode descrever, adequadamente, o movimento real. Se isto se consegue, ficará espelhada, no plano ideal, a vida da realidade pesquisada [...]. (MARX, 1975, p. 16).

O intento é captar o movimento da realidade e contribuir para a transformação social, destacando a realidade vivenciada pelas mulheres brasileiras, em uma perspectiva de aproximação, articulação e fortalecimento dos vínculos entre a Universidade e a sociedade. Validamos o pressuposto de que feminismo, transfeminismo e marxismo são teorias críticas que não se excluem e nem se contradizem, pois dialogam entre si e contribuem para apreensão de aspectos que conformam a realidade perquirida nessa pesquisa, como alternativas de análise, interpretação e transformação da realidade que as mulheres estão inseridas e das condições que estão submetidas.

Configurou-se como pesquisa qualitativa do tipo bibliográfica e documental, consultando várias fontes: levantamento bibliográfico/revisão da literatura para subsidiar a fundamentação teórica e as análises; levantamento documental da produção acadêmica no Brasil sobre Feminismo e Transfeminismo, no ínterim de 2015 a 2019, no Catálogo de teses e dissertações da Coordenação de Aperfeiçoamento de Pessoal de Nível Superior (Capes); e mapeamento de páginas e/ou perfis nas redes sociais do Facebook, Instagram e Twitter para o desenho do ciberativismo feminista e 


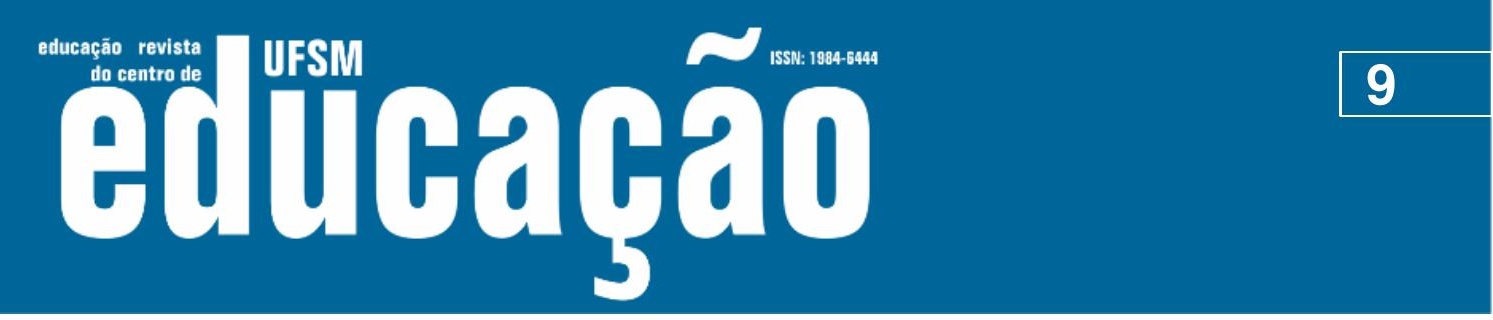

ISSN: 1984-6444 | http://dx.doi.org/10.5902/1984644446906

[...] como uma linha de pensamento e de prática feminista que rediscute a subordinação morfológica do gênero (como construção psicossocial) ao sexo (como biologia), condicionada por processos históricos, criticando-a como uma prática social que tem servido como justificativa para a opressão sobre quaisquer pessoas cujos corpos não estão conformes à norma binária homem/pênis e mulher/vagina [...]. (JESUS, 2014, p. 5).

Muitas das novas militantes são mulheres jovens, educadas na era digital, que passaram a juventude inteira ouvindo que homens e mulheres já tinham direitos iguais. Com a chegada à vida adulta e ao mercado de trabalho, elas se depararam com inúmeros sinais de que a igualdade entre os sexos ainda é uma ilusão e decidiram se organizar para transformar essa realidade. A forma democrática como os grupos são organizados, a diversidade das participantes e a pluralidade de reivindicações incentivam mulheres antes marginalizadas a aderir a alguma das bandeiras feministas e/ou transfeministas e começar a protestar por seus direitos.

$\mathrm{Na}$ quarta onda do feminismo, estariam as dezenas de milhares de mulheres que escrevem sobre o assédio, a discriminação e a liberdade sexual, incentivando-as a perceber que a desigualdade não é um problema individual, mas coletivo e que precisa de soluções políticas. Em vez de um movimento único, as novas feministas têm diferentes maneiras de protestar, formam grupos fragmentados e distintos, com causas muitas vezes semelhantes, porém cada movimento tem sua visão de feminismo e sua estratégia para buscar mais igualdade. Existe concordância de que as gerações do feminismo, quer em seus aspectos políticos quer nos aspectos teóricoepistemológicos, não podem ser entendidas em uma perspectiva histórica linear. Há até quem tenha trocado a palavra "feminismo" por "feminismos" - assim mesmo, no plural, isto porque seria difícil juntar todas as mulheres em um único movimento, dada a diversidade de suas necessidades e experiências. Isso não significa que o feminismo tenha se enfraquecido, ao contrário: ele se fortaleceu e avivou.

A tensão entre os diferentes feminismos é considerada positiva, pois nos mantém pensando sobre o tema, buscando respostas e tentando descobrir novas visões. Essa é uma das riquezas do feminismo atual, que ele seja múltiplo. Há uma grande movimentação de negras, latinas e lésbicas para se fazerem ouvir. Somadas, as vozes de múltiplos grupos diferentes podem soar mais fortes do que um movimento 


\section{Wusm Aitlathá}

ISSN: 1984-6444 | http://dx.doi.org/10.5902/1984644446906

as identidades coletivas feministas e transfeministas no ciberespaço, enquanto campo que expressa e potencializa epistemologias feministas e transfeministas, performatividades políticas e agendas de reivindicações das mulheres.

Os estudos de gênero e estudos feministas inauguram e/ou avivam, em áreas que já incorporam esses debates, práticas pedagógicas feministas e transfeministas que provocam transformações na formação profissional e política, e na atuação técnica e militante/ativista. Isso remete à comprovação de que é falsa a oposição entre ciência e política, assim como é falsa a dicotomia entre teoria e prática, pois são indissociáveis e juntas refletem a práxis socioeducativa, sociopolítica e sociocultural, que pode evocar e produzir melhorias nas condições objetivas e subjetivas de vida e existência das mulheres, alterando algumas realidades nos espaços públicos e/ou privados, apesar dos retrocessos e desafios hercúleos enfrentados face aos pilares históricos da estrutura patriarcal, capitalista, misógina, racista e cisheteronormativa ainda sobressalentes na sociedade.

\section{Expressões dos ciberativismos feministas e transfeministas}

Faz-se necessário mapear as expressões dos ciberativismos feministas e transfeministas na particularidade brasileira, porque são potentes espaços de organização, mobilização e lutas sociais, que fortalecem a capacidade de resistência das mulheres e de proposituras que incidem em melhores condições de vida às mulheres e à sociedade em geral.

Navegamos nas redes sociais Facebook, Instagram e Twitter para conhecer e apresentar o panorama do ciberativismo feminista e transfeminista no Brasil. A busca se referenciou nos descritores: Marcha, Frente Feminista, Frente Transfeminista, Coletivo Feminista, Coletivo Transfeminista. No termo Marcha, consideramos somente perfis com pautas feministas e transfeministas.

Acessamos 438 páginas: 434 perfis feministas (99,1\%); e apenas 4 transfeministas (0,9\%). Notamos maior representatividade dos Coletivos: 295 (67,3\%); na sequência as Frentes: 98 perfis (22,4\%) e a menor soma nas Marchas: 45 (10,3\%). Não delimitamos o ano para a localização das páginas, encontrando perfis criados no 


\section{تutดaดูão}

ISSN: 1984-6444 | http://dx.doi.org/10.5902/1984644446906

uma pré-candidatura feminista à vereança em São Paulo pautada no ecossocialismo e em defesa dos interesses das mulheres da classe trabalhadora".

O Coletivo Feminista Rosa Lilás Sorocaba9: 10.258 pessoas seguindo e 9.882 curtidas. É um Coletivo Feminista interseccional (contra machismo, racismo, LGBTfobias e pela luta de classe), enfatizando: "Lutamos pela emancipação da mulher e igualdade de gênero".

O Coletivo Feminista Carolina de Jesus ${ }^{10}: 9.436$ seguidoras/es e 9.090 curtem. Coletivo Feminista da UFSCar, Campus Sorocaba, formado por minas para as minas; Coletivo feminista (sem vertente única associada) idealizado em 2015 por algumas mulheres cansadas do patriarcado em uma salinha da UFSCar.

O Coletivo Feminista Flores de Frida ${ }^{11}: 8.683$ pessoas seguindo e 8.655 curtidas. Na descrição, menciona: "Somos um coletivo diversificado de universitárias que busca o empoderamento feminino a partir da sensibilização e participação ativa de mulheres". Surgiu da união das estudantes de diversos cursos da Unifacs Salvador, em prol da luta pelos direitos das mulheres.

O Coletivo Feminista Classista Ana Montenegro - Nacional12 com 8.678 seguidoras/es e 8.410 curtem: dirige suas ações nos interesses das trabalhadoras em luta contra a exploração capitalista. A Cunhã Coletivo Feminista ${ }^{13}: 7.503$ seguem e 7.375 curtidas. É uma organização social sem fins lucrativos que atua em João Pessoa (PB), no Nordeste do Brasil, desde 1990.

No mapeamento das Frentes, apuramos 98 páginas, criadas no intervalo de 2012 a 2020, sendo 100\% dos perfis feministas. Destacaremos 6 (seis) páginas com maior alcance nas redes sociais.

A Frente Feminista de Londrina - 8M Londrina ${ }^{14}$ soma 10.804 pessoas seguindo e 10.530 curtem. As Amazonas 15: 9.478 seguem e 9.445 curtidas. Em sua descrição, cita: é uma "Frente feminista criada por alunas da UTFPR - Pato Branco".

A Frente Feminista USP ${ }^{16}$ com 3.712 seguidoras/es e 3.691 curtem. A Frente Feminista de Esquerda ${ }^{17}$ totaliza 3.593 pessoas seguindo e 3.503 curtidas: é composta por coletivos feministas, organizações políticas e independentes para unificar a luta contra o machismo e a exploração. A Frente Feminista Mackenzista ${ }^{18}$ somando 3.512 que seguem e 3.502 curtem. 


\section{Aillbapẫ

ISSN: 1984-6444 | http://dx.doi.org/10.5902/1984644446906

das demandas, além de ser potência das lutas sociais feministas e transfeministas cotidianas. A mobilização das mulheres por meio das comunidades virtuais feministas e transfeministas culmina em levantes e atos nas ruas, visibilizando a agenda de lutas e dando concretude às propostas e ações que combatem opressões, explorações e violências de diferentes dimensões.

É inconteste que o ciberfeminismo, configurado como movimento social, "[...] consegue ressignificar elementos do feminismo a partir das novas tecnologias e dos espaços ocupados pelas mulheres". (DUTRA, 2018, p. 25). E, sem dúvidas, "extrapolar as fronteiras utilizando as redes sociais, fez mulheres das mais variadas classes sociais, religião, raça/etnia e gênero se unirem para a subversão no processo de comunicar e resistir". (DUTRA, 2018, p. 25).

\section{À guisa de conclusão}

Captamos que essa nova "onda" dos movimentos feministas no Brasil se apresenta como um momento analítico que elenca particularidades para os estudos e as teorias feministas e transfeministas a partir da proposta de um campo crítico das diferenças, de novos redesenhos dos movimentos feministas e transfeministas que estão redesenhando novas propostas teóricas. Esse processo se dá mediante uma renovada ênfase em fronteiras interseccionais, transversais e transdisciplinares de gênero, raça, sexualidade, classe, geração, territorialidade, entre outros marcadores.

As redes de ativismos feministas e transfeministas combativos estão redescobrindo a ideia do impossível, reivindicando tanto pão como rosas: o pão que décadas de neoliberalismo tiraram de nossas mesas, mas também a beleza que nutre nosso espírito por meio da euforia da rebelião. (ARRUZZA; BHATTACHARYA; FRASER, 2019).

O retrato da pesquisa no Brasil sobre feminismos e transfeminismos revela a importância da indissociabilidade entre teoria e prática, indicando a necessidade de potencializar a relação Universidade/sociedade, visto que os estudos evidenciam a apropriação e o aprofundamento das teorias como fundamento que alicerça as práticas sociais, políticas e educativas coletivas na direção de fortalecer as 


\section{Tusm Aillathá}

ISSN: 1984-6444 | http://dx.doi.org/10.5902/1984644446906

epistemologias feministas e transfeministas, os projetos políticos, as agendas reivindicatórias dos feminismos e transfeminismos, e as transformações provocadas e enlaçadas pelas contribuições teóricas e práticas dos estudos e levantes. Os movimentos (no ciberativismo e/ou nas ruas), as pautas, as lutas e as resistências feministas e transfeministas são mediadas pela interseccionalidade dos marcadores que constituem as objetividades e subjetividades das existências das protagonistas dos feminismos (históricos e de suas expressões contemporâneas), assim como das protagonistas dos transfeminismos em ascensão.

No mapeamento das redes sociais, descobrimos o arsenal de comunidades virtuais que ocupam o ciberespaço na dinâmica brasileira, mas interconectadas à conjuntura mundial, posto que os ciberativismos rompem as fronteiras limítrofes, antes impeditivas dos diálogos e das trocas de experiências. Embora tenha sido restrito às nomenclaturas Marchas, Frentes e Coletivos Feministas e Transfeministas, constituiu importante resultado para apresentar o legado e a multiplicidade dos ciberativismos feministas e transfeministas, e o papel de alargar a articulação e mobilização das mulheres por intermédio das redes, em constante diálogo entre os perfis e movimentos, e entre as realidades locais, regionais, nacionais e internacionais.

Avaliamos que essa combinação de discursos e práticas mobilizadoras (a um só tempo: históricas, políticas, educativas e sociais) que reconhecem a interseccionalidade das diferenças como dado inescapável e força politizadora das lutas sociais, é o que tem sido a tônica de movimentos feministas e transfeministas no Brasil e na América Latina, e de elementos muito significativos das forças transformadoras atuais das nossas sociedades.

\section{Referências}

ARRUZZA, Cinzia; BHATTACHARYA, Tithi; FRASER, Nancy. Feminismo para os 99\%: um manifesto. Tradução: Heci Regina Candiani. 1. ed. São Paulo: Boitempo, 2019. 


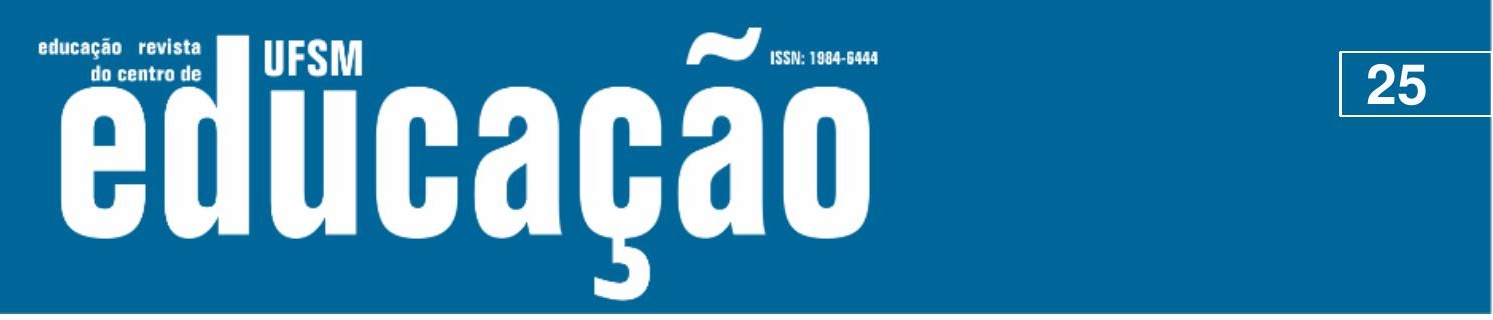

ISSN: 1984-6444 | http://dx.doi.org/10.5902/1984644446906

BUITONI, Dulcilia Schroeder; LOPES, Martha. "Revista AzMina" e Carnaval sem Assédio: uma análise do jornalismo ativista no combate à violência contra a mulher. Cadernos de Gênero e Diversidade, v. 4, n. 2, 2018, p. 21-40. Disponível em: https://periodicos.ufba.br/index.php/cadgendiv/article/view/24613/16005. Acesso em: 11 jun. 2021.

CASTELLS, Manuel. A sociedade em rede. São Paulo: Paz e Terra, 1999.

COSTA, Claudia de Lima. O sujeito no feminismo: revisitando os debates. Cadernos Pagu, Campinas. UNICAMP, v. 19, 2002, p. 59-90. Disponível em: https://www.scielo.br/pdf/cpa/n19/n19a04.pdf. Acesso em: 19 mar. 2020.

CRENSHAW, Kimberlé. Documento para o encontro de especialistas em aspectos da discriminação racial relativos ao gênero. Tradução: Liane Schneider. Rev. Estud. Fem. [online], Florianópolis, v. 10, n. 1, 2002, p. 171-188. Disponível em: https://www.scielo.br/pdf/ref/v10n1/11636.pdf. Acesso em: 11 mar. 2020.

CRUZ, Maria Helena Santana. A crítica feminista à ciência e contribuição à pesquisa nas ciências humanas. Revista de Estudos de Cultura da UFS, 2014, p. 15-27. Disponível em: http://www.seer.ufs.br/index.php/revtee/article/viewFile/2949/2596. Acesso em: 11 jan. 2020.

CRUZ, Maria Helena Santana; DIAS, Alfrancio Ferreira. Antifeminismo. Revista de Estudos de Cultura, n. 1, jan./abr., 2015, p. 33-42. Disponível em: https://trapiche.revistas.ufs.br/index.php/revec/article/view/3651. Acesso em: 13 fev. 2020.

DOMINGUES, José Maurício. Aproximações à América Latina: desafios contemporâneos. Rio de Janeiro: Civilização Brasileira, 2007.

DUTRA, Zeila Aparecida Pereira. A Primavera das Mulheres: Ciberfeminismo e os Movimentos Feministas. Revista Feminismos, Salvador, v. 6, n. 2, 2018, p. 19-31. Disponível

em:

https://periodicos.ufba.br/index.php/feminismos/article/view/30384/17906. Acesso em: 11 jun. 2021.

HARAWAY, Donna. Manifesto ciborgue: ciência, tecnologia e feminismo-socialista no final do século XX. In: HARAWAY, Donna; KUNZRU, Hari; TADEU, Tomaz. (Orgs.). Antropologia do ciborgue: as vertigens do pós-humano. Belo Horizonte: Autêntica, 2000, p. 33-118.

HARDING, Sandra. A instabilidade das categorias analíticas na teoria feminista. Estudos Feministas, Florianópolis, v. 1, n. 1, 1993, p. 7-31. Disponível em: https://periodicos.ufsc.br/index.php/ref/article/view/15984/14483. Acesso em: 17 nov. 2019. 


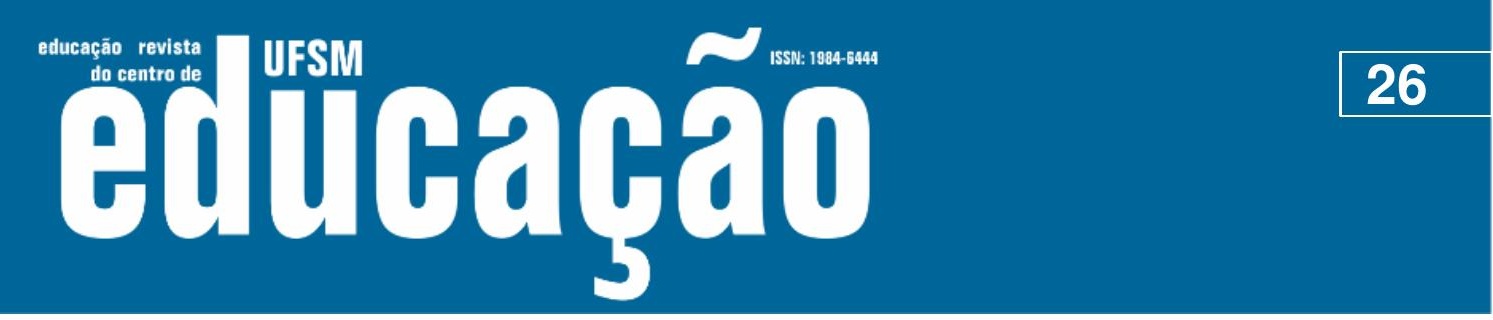

ISSN: 1984-6444 | http://dx.doi.org/10.5902/1984644446906

JESUS, Jaqueline Gomes de. Interlocuções teóricas do pensamento transfeminista. In: JESUS, Jaqueline Gomes de [et. al.]. (Org.). Transfeminismo: teorias e práticas. Rio de Janeiro: Metanoia, 2014, p. 3-18.

LOURO, Guacira Lopes. Gênero, história e educação: construção e reconstrução. Educação e Realidade, Faculdade de Educação da Universidade Federal do Rio Grande do Sul, v. 20, n. 2, 1995, p. 101-132. Disponível em: https://seer.ufrgs.br/educacaoerealidade/article/view/71722. Acesso em: 13 fev. 2020.

LOURO, Guacira Lopes. Gênero, sexualidade e educação: uma perspectiva pósestruturalista. Petrópolis: Vozes, 1999.

MARX, Karl. O capital: crítica da economia política. Rio de Janeiro: Civilização Brasileira, 1975.

MATOS, Marlise. Movimento e teoria feminista: é possível reconstruir a teoria feminista a partir do Sul Global? Revista de Sociologia e Política, v. 18, n. 36, jun., 2010, p. 67-92. Disponível em: https://www.scielo.br/pdf/rsocp/v18n36/06.pdf. Acesso em: 3 mai. 2020.

NATANSOHN, Graciela; REIS, Josemira Silva. Com quantas hashtags se constrói um movimento? O que nos diz a "Primavera Feminista" brasileira. Tríade: Revista de Comunicação, Cultura e Mídia, Sorocaba, SP, v. 5, n. 10, 2017, p. 113-130. Disponível em: http://periodicos.uniso.br/ojs/index.php/triade/article/view/3096/2817. Acesso em: 12 jun. 2021.

PRÁ, Jussara Reis. O feminismo como teoria e como prática. In: STREY, Marlene Neves. (Org.). Mulher: Estudos de gênero. São Leopoldo: UNISINOS, 1997, p. 39-57.

PEDRO, Joana Maria. O feminismo de "segunda onda". Corpo, Prazer e Trabalho. In: PINSKY, Carla Bassanezi; PEDRO, Joana Maria. (Orgs.). Nova história das mulheres no Brasil. São Paulo: Contexto, 2012, p. 238-259.

PINTO, Céli Regina Jardim. Uma história do feminismo no Brasil. Coleção História do Povo Brasileiro. São Paulo: Editora Fundação Perseu Abramo, 2003.

RAGO, Margareth. Entre a história e a liberdade: Luce Fabbri e o anarquismo contemporâneo. São Paulo: Editora UNESP, 2001.

SAFFIOTI, Heleieth lara Bongiovani. Gênero, patriarcado e violência. São Paulo: Perseu Abramo, 2004.

SCOTT, Joan Wallach. Gender: A useful category of historical analysis. The American Historical Review, 91(5), 1986, p. 1053-1101. 


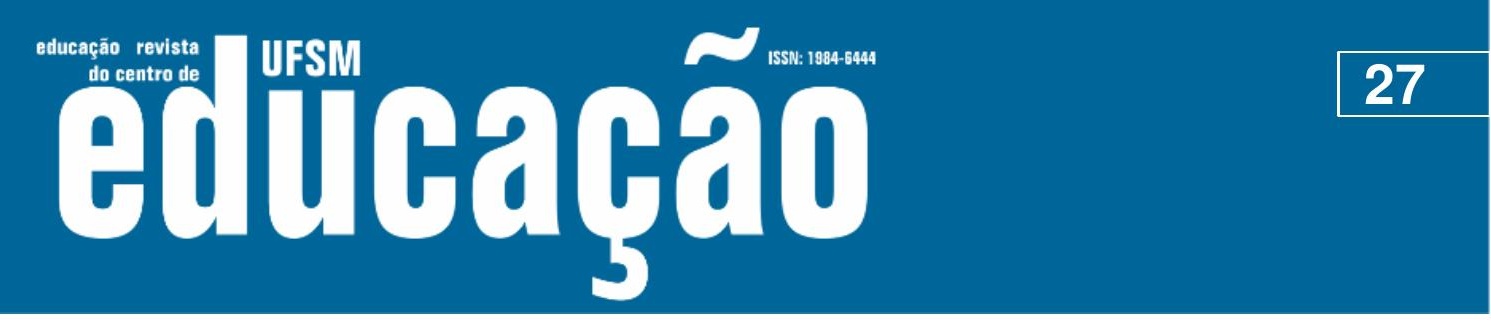

ISSN: 1984-6444 | http://dx.doi.org/10.5902/1984644446906

SCOTT, Joan Wallach. Gênero: uma categoria útil de análise histórica. Tradução: Guacira Lopes Louro. Educação \& Realidade, Porto Alegre, v. 20, n. 2, jul./dez., 1995, p. 71-99. Disponível em: https://seer.ufrgs.br/index.php/educacaoerealidade/article/view/71721. Acesso em: 13 fev. 2020.

SWAIN, Tânia Navarro. Feminismo e representações sociais. In: História: Questões \& Debates, Curitiba: Editora da UFPR, n. 34, 2001, p. 11-44.

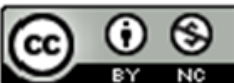

This work is licensed under a Creative Commons Attribution-NonCommercial 4.0 International (CC BY-NC 4.0)

\section{Notas}

1 Algumas posições, ainda que heterogêneas, distinguem os Estudos Feministas - cujo foco se dá principalmente em relação ao estudo das e pelas mulheres, mantidas as estreitas relações entre teoria e política-militância feminista - dos Estudos de Gênero, cujos pressupostos abarcam a compreensão do gênero enquanto categoria sempre relacional. (SCOTT, 1986).

2 Uma 'quarta onda' é apontada (MATOS, 2010), na perspectiva teórico-acadêmica, referente ao feminismo do Sul (ancorado em teorias latino-americanas e brasileiras) para o Norte global (ancorado em teorias anglo-saxônicas), tomada como luz a nortear futuros estudos, pautados nas teorias feministas de dimensões sócio-históricas e culturais brasileira e latino-americana.

3 Disponível em: https://www.facebook.com/ColetivaMatinta/. Acesso em: 5 jan. 2021.

${ }^{4}$ Disponível em: https://www.facebook.com/ColetivoFeminista/. Acesso em: 4 jan. 2021.

${ }^{5}$ Disponível em: https://www.instagram.com/coletivo_feminista/. Acesso em: 5 jan. 2021.

${ }^{6}$ Disponível em: https://www.instagram.com/coletivo_feminista/. Acesso em: 5 jan. 2021.

7 Disponível em: https://www.facebook.com/mariellecoletivo/. Acesso em: 5 jan. 2021.

8 Disponível em: https://www.facebook.com/bancadafeministapsol/. Acesso em: 5 jan. 2021.

9 Disponível em: https://www.facebook.com/RosaLilasSorocaba/. Acesso em: 5 jan. 2021.

10 Disponível em: https://www.facebook.com/CFCarolinaJesus/. Acesso em: 5 jan. 2021.

11 Disponível em: https://www.facebook.com/Coletivo-Feminista-Flores-de-Frida-255502588127983/. Acesso em: 5 jan. 2021.

12 Disponível em: https://www.facebook.com/CFCAMBR/. Acesso em: 5 jan. 2021.

${ }^{13}$ Disponível em: https://www.facebook.com/cunhanfeminista/. Acesso em: 4 jan. 2021.

${ }^{14}$ Disponível em: https://www.facebook.com/frentefeministadelondrina/. Acesso em: 6 jan. 2021.

15 Disponível em: https://www.facebook.com/FrenteAsAmazonas/. Acesso em: 6 jan. 2021.

${ }^{16}$ Disponível em: https://www.facebook.com/frentefeminista.usp/. Acesso em: 6 jan. 2021.

17 Disponível em: https://www.facebook.com/FrenteFeministaDeEsquerda/. Acesso em: 6 jan. 2021.

${ }^{18}$ Disponível em: https://www.facebook.com/frentefemmack/. Acesso em: 6 jan. 2021. 


\section{Len

ISSN: 1984-6444 | http://dx.doi.org/10.5902/1984644446906

19 Disponível em: https://www.facebook.com/frentedasmulheres/. Acesso em: 6 jan. 2021.

20 Disponível em: https://www.facebook.com/Marchamnegra/. Acesso em: 6 jan. 2021.

${ }^{21}$ Disponível em: https://twitter.com/marchamulheres. Acesso em: 6 jan. 2021.

22 Disponível em: https://www.facebook.com/MarchaDasVadiasSP/. Acesso em: 6 jan. 2021.

${ }^{23}$ Disponível em: https://www.facebook.com/marchadasvadiasdf/. Acesso em: 15 dez. 2020.

24 Disponível em: https://www.instagram.com/marchamulheres/. Acesso em: 6 jan. 2021.

25 Disponível em: https://www.instagram.com/orgulhotrans/. Acesso em: 6 jan. 2021.

${ }^{26}$ Disponível em: https://www.facebook.com/marchadasvadiascwb/. Acesso em: 15 dez. 2020.

27 Disponível em: https://www.facebook.com/marchadasvadias/. Acesso em: 15 dez. 2020.

${ }^{28}$ Disponível em: https://www.facebook.com/mmnegrasSP. Acesso em: 13 dez. 2020. 